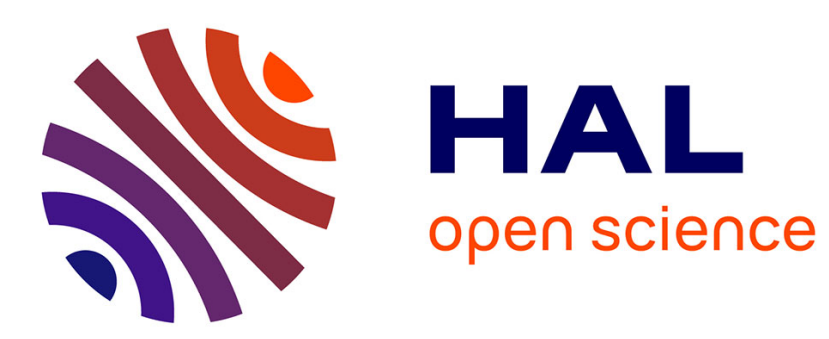

\title{
Cross-cluster transition-metal bonding in oblato-nido dimetallaboranes unveiled by topological analysis
}

Benoît Boucher, Jean-François Halet, Miroslav Kohout

\section{To cite this version:}

Benoît Boucher, Jean-François Halet, Miroslav Kohout. Cross-cluster transition-metal bonding in oblato-nido dimetallaboranes unveiled by topological analysis. Computational and Theoretical Chemistry, 2015, 1068, pp.134-141. 10.1016/j.comptc.2015.06.029 . hal-01174900

HAL Id: hal-01174900

https://hal-univ-rennes1.archives-ouvertes.fr/hal-01174900

Submitted on 25 Nov 2015

HAL is a multi-disciplinary open access archive for the deposit and dissemination of scientific research documents, whether they are published or not. The documents may come from teaching and research institutions in France or abroad, or from public or private research centers.
L'archive ouverte pluridisciplinaire HAL, est destinée au dépôt et à la diffusion de documents scientifiques de niveau recherche, publiés ou non, émanant des établissements d'enseignement et de recherche français ou étrangers, des laboratoires publics ou privés. 


\title{
Cross-cluster transition-metal bonding in oblato-nido dimetallaboranes unveiled by topological analysis
}

\author{
Benoît Boucher \\ Institut des Sciences Chimiques de Rennes, UMR 6226 CNRS-Ecole Nationale Supérieure de Chimie de Rennes-Université de Rennes 1, \\ Avenue du Général Leclerc, 35042 Rennes, France \\ Max-Planck-Institut für Chemische Physik fester Stoffe, Nöthnitzer Strasse 40, 01187 Dresden, Germany \\ Jean-François Halet \\ Institut des Sciences Chimiques de Rennes, UMR 6226 CNRS-Ecole Nationale Supérieure de Chimie de Rennes-Université de Rennes 1, \\ Avenue du Général Leclerc, 35042 Rennes, France
}

Miroslav Kohout*

Max-Planck-Institut für Chemische Physik fester Stoffe, Nöthnitzer Strasse 40, 01187 Dresden, Germany

\begin{abstract}
The bonding situation for the oblato-nido dimetallaboranes $(\mathrm{CpV})_{2} \mathrm{~B}_{5} \mathrm{H}_{11}$ and $\left(\mathrm{Cp}^{*} T\right)_{2} \mathrm{~B}_{5} \mathrm{H}_{5+x}$, where $T=\mathrm{Ta}$, $\mathrm{Cr}$, Mo, $\mathrm{W}$, Re and $\mathrm{Cp}^{*}=\mathrm{C}_{5} \mathrm{Me}_{5}$, was analyzed using the corresponding model series with $\mathrm{Cp}^{*}$ replaced by the cyclopentadienyl $\mathrm{C}_{5} \mathrm{H}_{5}$. The application of different bonding indicators revealed that both through-space and through-bond (via boron atoms of the ring) interactions account for a substantial metal-metal bond.
\end{abstract}

Keywords: Metal-metal bond, Atoms in molecules, Delocalization index, Electron localizability indicator

\section{Introduction}

There are today over hundred molecular dimetallab- ${ }^{25}$ oranes, which have been synthesized and characterized with nearly all the transition metals $(T)$, both early and 5 late metals (see for example Fehlner et al.[1-3]). They constitute a class of compounds which has revealed numerous possibilities for the way metal and borane fragments interact to generate novel structures, demonstrating the important role for the transition metal in the struc10 tural arrangements which are observed. Among these compounds the molecules $(\mathrm{CpV})_{2} \mathrm{~B}_{5} \mathrm{H}_{11},[4]\left(\mathrm{Cp}^{*} \mathrm{Cr}\right)_{2} \mathrm{~B}_{5} \mathrm{H}_{9},[5]$ $\left(\mathrm{Cp}^{*} \mathrm{Mo}\right)_{2} \mathrm{~B}_{5} \mathrm{H}_{9},[6](\mathrm{Cp} * \mathrm{Ta})_{2} \mathrm{~B}_{5} \mathrm{H}_{11},[6]\left(\mathrm{Cp}^{*} \mathrm{~W}\right)_{2} \mathrm{~B}_{5} \mathrm{H}_{9},[3]$ and $(\mathrm{Cp} * \mathrm{Re})_{2} \mathrm{~B}_{5} \mathrm{H}_{2} \mathrm{Cl}_{5}[7]$, whereby $\mathrm{Cp}^{*}=\mathrm{C}_{5} \mathrm{Me}_{5}$, constitute examples of early transition-metal dimetallaboranes which 15 all adopt the same open and flattened hexagonal bipyramidal nido geometry and possess the electron count of $12_{40}$ cluster valence electrons. Their structural peculiarities are the oblate (i. e., flattened) shape (these compounds are termed as oblato-nido species)[8] and the fact that the metal atoms occupy opposite vertexes in such a way that the $T$ - $T$ distance is consistent with possible existence of ${ }_{45}$ a cross-cluster bonding interaction. Indeed, short $T-T^{45}$ distances have been measured experimentally. [3-7] Such

\footnotetext{
${ }^{*}$ Corresponding author

Email address: kohout@cpfs.mpg.de (Miroslav Kohout)
}

structures are apparently highly hypoelectronic and do not obey the Wade-Mingos rules[9-11] as generally do boranes, carboranes and late-transition metallaboranes. Density functional theory (DFT) calculations have been able to sort out this apparent systematic rule deviation, [7] but the proximity of the two metal atoms on opposite sides in the flattened direction allows some speculation about the nature of $T-T$ interaction. This has been tackled several times in the literature using $\mathrm{MO}$ analysis. [1, 2, 7, 8, 12-20] However, whereas the conclusions seem to fully converge with some studies evidencing a single $T$ - $T$ bond, [7] some others suggest a formal internal $T$ - $T$ double bond. [8]

In the following, the through-space $T$ - $T$ interaction in the $\mathrm{Cp}_{2} \mathrm{~B}_{5} \mathrm{H}_{5+x}$ model series, with the number of bridging $\left(\mathrm{H}_{\mathrm{b}}\right)$ atoms $x=6$ for $\mathrm{V}$, Ta, $x=4$ for $\mathrm{Cr}$, Mo, W, and $x=2$ for Re, respectively, is analyzed. The investigation was performed using the electron density and its derivatives within the framework of the quantum theory of atoms in molecules [21] (QTAIM), as well as utilizing several bonding indicators like the delocalization indices $[22,23]$ (DI), the Fermi orbitals (FO) from the domainaveraged Fermi-hole analysis[24-26] (DAFH), the covalent bond order from the evaluation of localized natural orbitals (LNO), [27] and the electron localizability indicator ELI-D.[28, 29] 


\section{Theory section}

\subsection{Electronic structure calculations}

The calculations were performed with the Gaussian09 program [30] at the density-functional level of theory (DFT). The computational demand for the oblato-nido species, $\mathrm{cf}$. Fig. 1, was reduced replacing $\mathrm{Cp}^{*}=\mathrm{C}_{5} \mathrm{Me}_{5}$ by $\mathrm{Cp}=\mathrm{C}_{5} \mathrm{H}_{5}$

${ }_{55}$ and $\mathrm{Cl}$ by $\mathrm{H}$. This substitution is not expected to have significant influence on the analysis. The atoms $\mathrm{H}, \mathrm{B}, \mathrm{C}$ and $\mathrm{O}$ were described by the $6-31 \mathrm{G}^{* *}$ basis sets and the $T$ atoms by the corresponding LANL2DZ basis sets utilizing effective core potentials. For the DFT calculations ${ }_{60}$ the BVP86 functional was used. [31-33] The structure of ${ }_{90}$ the examined model systems was optimized and the harmonic vibrational frequencies were computed to check the stationarity of the optimized geometries.

\subsection{Methods}

The calculation of the bonding indicators and the topological analysis was performed with the DGrid-4.6 program. The electron density, the ELI-D, and the Fermi orbitals were computed on equidistant grids using a 0.1 bohr mesh size.

Following the QTAIM approach the electron density was searched for critical points (points of zero density gradient in case of Gaussian basis) and several properties were evaluated at the saddle points (so-called bondcritical points, $b c p$ ). For each $b c p$ the bond path, represent75 ing the bonding interaction, was computed. The density basins (spatial regions enclosed by density-gradient zeroflux surfaces) were determined and the electronic population within evaluated, leading to the effective charges of the atomic regions. Additionally, the overlap integrals over the QTAIM basins were computed. Those were utilized to compute the delocalization indices (DI), connected with the bond order, as well as the Fermi orbitals (FO) and the $e^{100}$ localized natural orbitals (LNO).

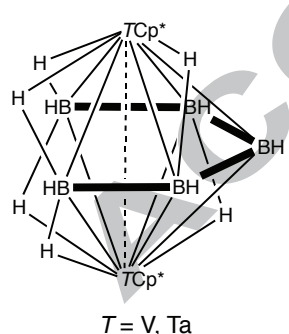

$T=\mathrm{V}, \mathrm{Ta}$
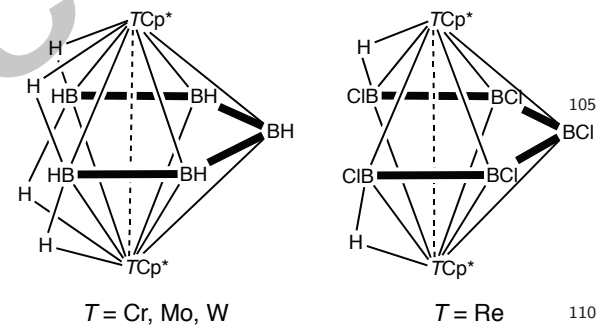

Figure 1: The oblato-nido species.

\section{Results and discussions}

\subsection{Structure optimization}

The experimental interatomic distances between the two transition metals, together with the (averaged) distances from the $T$ to the carbon and boron, respectively, ${ }^{120}$
Table 1: Interatomic Distances from Experiment $(\AA)$.

in the oblato-nido species under consideration are compiled in Table 1.

The geometry optimization of the corresponding model systems results in $T$ - $T$ distances deviating from the experimental ones within few pm only, cf. the data reported in Table 2 (see Supplementary data for the optimized model ${ }_{5}$ structures). In case of $(\mathrm{CpRe})_{2} \mathrm{~B}_{5} \mathrm{H}_{7}$ the trans configuration of the two $\mathrm{H}_{\mathrm{b}}$ atoms is energetically more favorable 34] than the cis configuration as proposed earlier by others. [7]

\begin{tabular}{|c|c|c|c|}
\hline compound & $T-T$ & $T-\mathrm{C}^{a}$ & $T-\mathrm{B}^{a}$ \\
\hline$(\mathrm{CpV})_{2} \mathrm{~B}_{5} \mathrm{H}_{11}$ & 2.691 & 2.281 & 2.221 \\
\hline$(\mathrm{CpCr})_{2} \mathrm{~B}_{5} \mathrm{H}_{9}$ & 2.595 & 2.206 & 2.155 \\
\hline$(\mathrm{CpMo})_{2} \mathrm{~B}_{5} \mathrm{H}_{9}$ & 2.828 & 2.364 & 2.266 \\
\hline$(\mathrm{CpTa})_{2} \mathrm{~B}_{5} \mathrm{H}_{11}$ & 2.938 & 2.423 & 2.338 \\
\hline$(\mathrm{CpW}){ }_{2} \mathrm{~B}_{5} \mathrm{H}_{9}$ & 2.831 & 2.356 & 2.264 \\
\hline$(\mathrm{CpRe})_{2} \mathrm{~B}_{5} \mathrm{H}_{7}$ & 2.745 & 2.315 & 2.201 \\
\hline
\end{tabular}
a averaged.

\subsection{Bond paths}

The evaluation of the critical points of the electron density distribution $\rho$ followed by the search for the bond paths, i.e., field lines of $\nabla \rho$ connecting bond-critical points (saddle points) with attractors ( $\rho$ maxima) yields so-called molecular graph.[21] For each model system the corresponding molecular graph, cf. Fig. 2 closely resembles the classical chemical structure diagrams. The metal atoms are linked by a bond path to each carbon of the close Cp ligand. In case of the bridging hydrogens the corresponding paths are strongly curved, whereby the metal-boron path is not present, in contrast to Fig. 1 where the closest interatomic contacts are just schematically depicted.

The presence of $T$ - $T$ bonding interaction, as suggested by the short interatomic distance, was clearly confirmed by the existence of the bond-critical point and the corresponding bond path connecting the two metals. The

\begin{tabular}{lccc}
\hline compound & $T-T$ & $T-\mathrm{C}^{a}$ & $T-\mathrm{B}^{a}$ \\
\hline$(\mathrm{CpV})_{2} \mathrm{~B}_{5} \mathrm{H}_{11}$ & $2.7604(10)[4]$ & 2.247 & 2.217 \\
$\left(\mathrm{Cp}{ }^{*} \mathrm{Cr}\right)_{2} \mathrm{~B}_{5} \mathrm{H}_{9}$ & $2.6246(9)[6]$ & 2.198 & 2.147 \\
$\left(\mathrm{Cp}{ }^{*} \mathrm{Mo}\right)_{2} \mathrm{~B}_{5} \mathrm{H}_{9}$ & $2.8085(6)[6]$ & 2.328 & 2.248 \\
$\left(\mathrm{Cp}{ }^{*} \mathrm{Ta}\right)_{2} \mathrm{~B}_{5} \mathrm{H}_{11}$ & $2.9261(4)[5]$ & 2.384 & 2.326 \\
$\left(\mathrm{Cp}{ }^{*} \mathrm{~W}\right)_{2} \mathrm{~B}_{5} \mathrm{H}_{9}$ & $2.8170(8)[3]$ & 2.326 & 2.239 \\
$\left(\mathrm{Cp}{ }^{*} \mathrm{Re}\right)_{2} \mathrm{~B}_{5} \mathrm{H}_{2} \mathrm{Cl}_{5}$ & $2.7641(3)[7]$ & 2.292 & 2.201 \\
\hline averaged. & & &
\end{tabular}
tems. The density Laplacian at the $b c p$ is positive in all cases, cf. Table 3, thus showing a charge depletion which would mark a "closed-shell" interaction. However, this is a situation not untypical for the $d$-metals $[35,36]$. Because of the relatively high electron density at the $b c p$ (higher than twice the density of overlapping atoms) as well as 


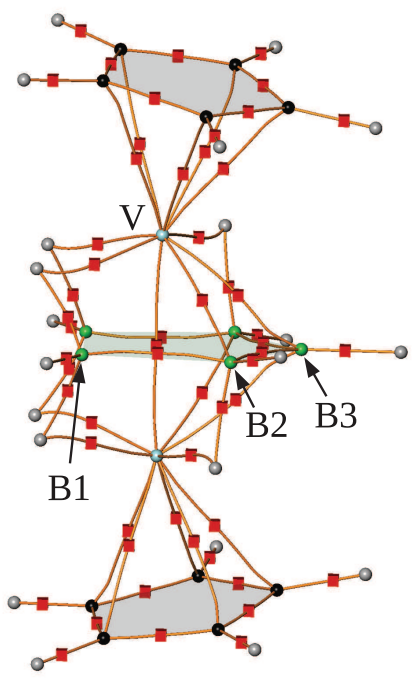

1

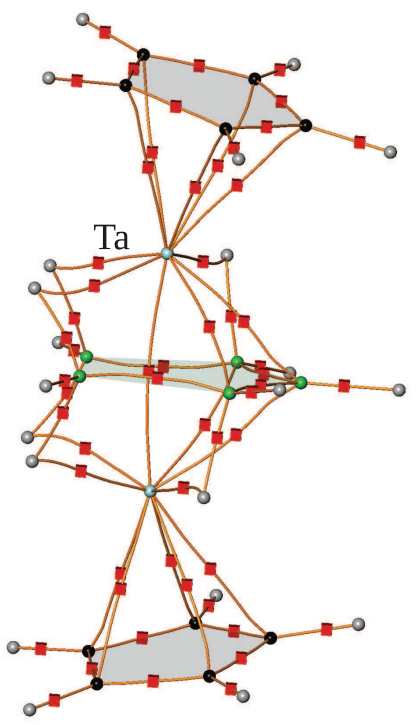

4

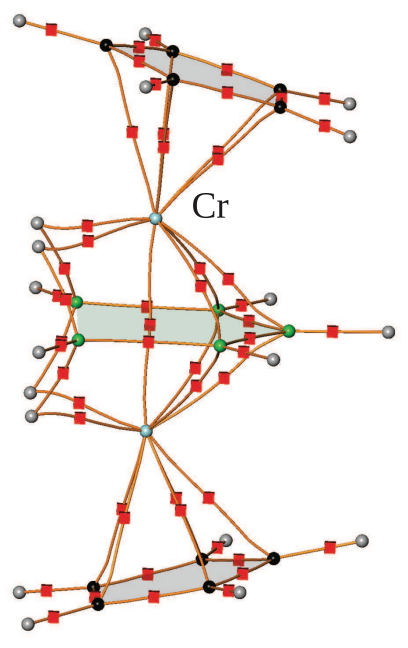

2

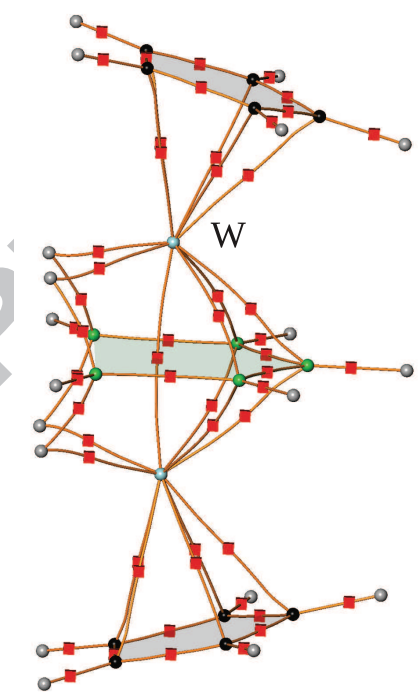

5
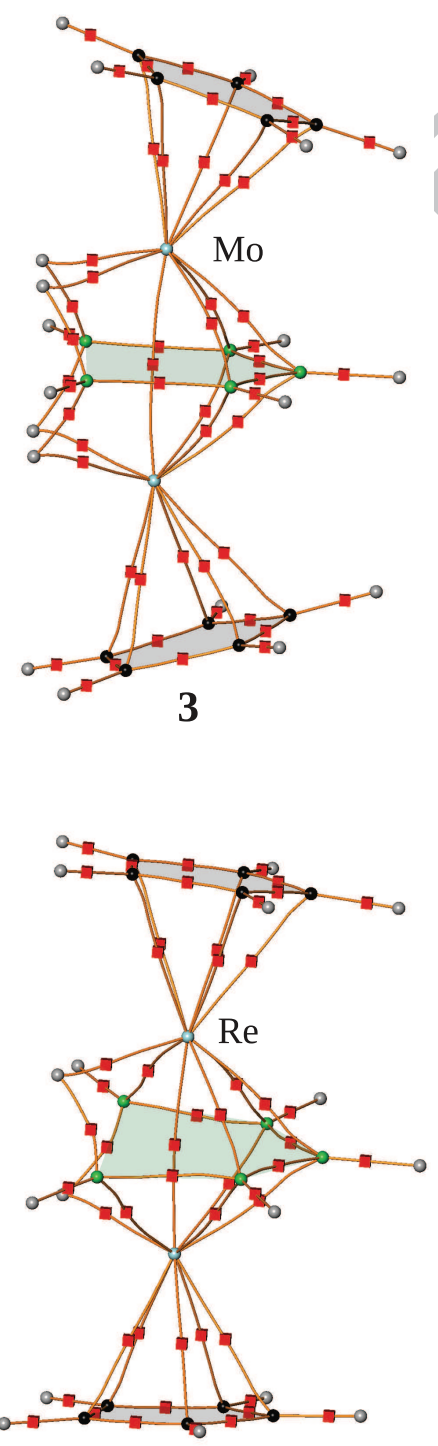

6

Figure 2: Molecular graphs for the model systems $(\mathrm{CpV})_{2} \mathrm{~B}_{5} \mathrm{H}_{11}(\mathbf{1}),(\mathrm{CpCr})_{2} \mathrm{~B}_{5} \mathrm{H}_{9}(\mathbf{2}),(\mathrm{CpMo})_{2} \mathrm{~B}_{5} \mathrm{H}_{9}(\mathbf{3}),(\mathrm{CpTa})_{2} \mathrm{~B}_{5} \mathrm{H}_{11}(\mathbf{4}),(\mathrm{CpW})_{2} \mathrm{~B}_{5} \mathrm{H}_{9}$ (5), $(\mathrm{CpRe})_{2} \mathrm{~B}_{5} \mathrm{H}_{7}(\mathbf{6})$. The bond critical points are represented by red cubes, the atoms by spheres (transition metal: blue; carbon: black; boron: green; hydrogen: gray). 
the negative (though small) value of the energy density $H$ (as indicated by the bond degree $H / \rho[37]$ ) the $T$ - $T$ interaction has a covalent character. Only for the Cr complex the $|V| / G$ ratio is close to 1 , showing that the potential energy does not unfold the appropriate stabilizing influence on the $\mathrm{Cr}-\mathrm{Cr}$ bond. Besides the $\mathrm{V}$ complex all the other systems yield a $|V| / G$ ratio close to 2 , from where the density Laplacian at the $b c p$ would revert from depletion to charge accumulation. The local kinetic energy $G / \rho$ exhibit relatively constant behavior at the $b c p$ (values between 0.4-0.5 hartree/e). This again renders the largest charge depletion as shown by the Cr compound.

Table 3: Properties at the $b c p$ Between the Transition Metals.

\begin{tabular}{cccccc}
\hline$T-T$ & $\rho$ & $\nabla^{2} \rho$ & $H / \rho$ & $G / \rho$ & $|V| / G$ \\
\hline V-V & 0.31 & 1.48 & -0.15 & 0.48 & 1.31 \\
Cr-Cr & 0.34 & 2.19 & -0.09 & 0.54 & 1.16 \\
Mo-Mo & 0.38 & 0.76 & -0.33 & 0.47 & 1.70 \\
Ta-Ta & 0.35 & 0.30 & -0.34 & 0.40 & 1.85 \\
W-W & 0.43 & 0.38 & -0.36 & 0.42 & 1.85 \\
Re-Re & 0.48 & 1.01 & -0.36 & 0.50 & 1.70 \\
\hline
\end{tabular}

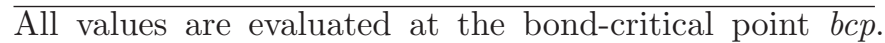
The electron density $\rho\left[\mathrm{e} \AA^{-3}\right]$, the density Laplacian $\nabla^{2} \rho$ $\left[\mathrm{e} \AA^{-5}\right]$, the bond degree $H / \rho$ [he $\left.{ }^{-1}\right]$, the local kinetic energy $G / \rho\left[\mathrm{he}^{-1}\right]$, and the local virial ratio $|V| / G$ are given.

\subsection{Atomic charges}

As the bonding interaction between the transition metals has been established by the above analysis at the $b c p^{165}$ in the boron plane, let us proceed with the examination of the constituent $T$ atoms. The electron density basins represent the atomic domains in the QTAIM approach. The effective charge of the atomic basins (cropped by the 6.75 $10^{-5} \mathrm{e} \AA^{-3}$ density isosurface) assigned to the transition metals is positive for all the examined compounds, cf. Table 4 , ranging from +0.9 for the $\mathrm{Cr}$ complex up to +1.7 for the Ta complex. The transition metals are connected to the negatively charged $\mathrm{Cp}$ rings $(-0.14$ to -0.37 , with carbon charges around -0.1). Also the bridging $\left(\mathrm{H}_{\mathrm{b}}\right)$ as well as the terminal $\left(\mathrm{H}_{\mathrm{t}}\right)$ hydrogens are always negative, with charge around -0.5 and -0.6 , respectively. The boron atoms are of course positive, whereby the terminal boron atoms (B1, cf. Fig. 2) exhibit the highest charge around +0.9 to +1.1 (only +0.7 for the Re complex). The boron atoms $\mathrm{B} 2$ contribute around $1 / 2-1 / 3$ and the mid boron ${ }_{170}$ B3 only roughly $1 / 3$ of this value.

\subsection{Delocalization indices}

With the QTAIM basins at hand the electron pair density $\rho_{2}\left(\vec{r}_{1}, \vec{r}_{2}\right)$ can be integrated over these atomic domains ${ }^{175}$ yielding the number of electron pairs formed between the regions. Subtracting this result from the number of quasiindependent electron pairs (i.e., the product of basin pop-
Table 4: Effective Charges for the QTAIM Basins.

\begin{tabular}{cccccccc}
\hline $\mathrm{cpd}$ & $T$ & $\mathrm{~B} 1$ & $\mathrm{~B} 2$ & $\mathrm{~B} 3$ & $\mathrm{H}_{\mathrm{t}}$ & $\mathrm{H}_{\mathrm{b}}$ & $\mathrm{Cp}$ \\
\hline $\mathbf{1}$ & 1.18 & 1.10 & 0.60 & 0.32 & -0.56 & -0.47 & -0.20 \\
$\mathbf{2}$ & 0.93 & 1.09 & 0.32 & 0.35 & -0.56 & -0.47 & -0.14 \\
$\mathbf{3}$ & 1.14 & 1.02 & 0.30 & 0.31 & -0.57 & -0.47 & -0.22 \\
$\mathbf{4}$ & 1.70 & 0.99 & 0.54 & 0.19 & -0.57 & -0.50 & -0.37 \\
$\mathbf{5}$ & 1.38 & 0.92 & 0.27 & 0.25 & -0.57 & -0.47 & -0.29 \\
$\mathbf{6}$ & 0.86 & 0.67 & 0.36 & 0.35 & -0.58 & -0.38 & -0.21 \\
\hline
\end{tabular}

See Fig. 2 for boron atom numbering.

DI $\delta\left(A_{i}, A_{j}\right)$ between two atomic domains $A_{i}$ and $A_{j}$ :

$$
\begin{aligned}
\frac{1}{2} \delta\left(A_{i}, A_{j}\right)= & \int_{A_{i}} \rho\left(\vec{r}_{1}\right) d \vec{r}_{1} \int_{A_{j}} \rho\left(\vec{r}_{2}\right) d \vec{r}_{2} \\
& -\int_{A_{i}} d \vec{r}_{1} \int_{A_{j}} \rho_{2}\left(\vec{r}_{1}, \vec{r}_{2}\right) d \vec{r}_{2}
\end{aligned}
$$

quantifies the number of electron pairs shared between the regions. In case of single-determinantal wavefunction the DI can be expressed using the overlap integrals between the orbitals $\{\phi\}, S_{m n}\left(A_{i}\right)=\int_{A_{i}} \phi_{m}(\vec{r}) \phi(\vec{r})_{n}^{*} d \vec{r}$, over the domain $A_{i}$ :

$$
\delta\left(A_{i}, A_{j}\right)=2 \sum_{m n} S_{m n}\left(A_{i}\right) S_{n m}\left(A_{j}\right) .
$$

When the integration runs over a single basin, i.e., $A_{i}=A_{j}$ the resulting value is termed the localization index $\lambda\left(A_{i}\right)$. DI also serves as specific topological definition of the bond order.[38] For metal complexes usually metal-metal DIs around $0.4-0.5$ are found together with significant metalligands DI values. [36, 39]

Table 5: Delocalization Indices $\delta(T, A)$ Between the Transition Metal $T$ and the Atomic Region $A$.

\begin{tabular}{cccccc}
\hline $\mathrm{cpd}$ & $\delta\left(T, T^{\prime}\right)$ & $\delta(T, \mathrm{~B})$ & $\delta\left(T, \mathrm{~B}_{\mathrm{b}}\right)$ & $\delta\left(T, \mathrm{H}_{\mathrm{b}}\right)$ & $\delta(T, \mathrm{C})$ \\
\hline $\mathbf{1}$ & 0.59 & 0.48 & 0.26 & 0.37 & 0.30 \\
$\mathbf{2}$ & 0.73 & 0.56 & 0.28 & 0.43 & 0.35 \\
$\mathbf{3}$ & 0.64 & 0.61 & 0.31 & 0.47 & 0.34 \\
$\mathbf{4}$ & 0.42 & 0.49 & 0.27 & 0.39 & 0.28 \\
$\mathbf{5}$ & 0.60 & 0.60 & 0.34 & 0.49 & 0.34 \\
$\mathbf{6}$ & 0.65 & 0.68 & 0.43 & 0.62 & 0.39 \\
\hline
\end{tabular}

Table 5 reveals that for the investigated systems the DIs $\delta\left(T, T^{\prime}\right)$ between the metals are relatively high, reaching values up to 0.73 for the $\mathrm{Cr}$ complex. This finding further corroborates the presence of a direct $T$ - $T$ bond. The transition metals have also substantial electron-pair sharing $\delta(T, \mathrm{~B}) \approx 0.6$ with each unbridged boron contact. Especially for the Re complex the sharing $\delta(T, \mathrm{~B} 1)=0.89$ with the terminal boron is much higher than the averaged value $\delta(T, \mathrm{~B})=0.68$ in Table 5 (this feature is reflected also in the ELI-D analysis, see later). The exclusion of this $\mathrm{DI}$ value would reduce the average for the Re complex to $\delta(T, \mathrm{~B})=0.61$. The sharing $\delta\left(T, \mathrm{~B}_{\mathrm{b}}\right)$ with the boron of the $T-\mathrm{H}-\mathrm{B}$ bridge is about half of the DI for the unbridged 
contact. However, interestingly, the pair sharing $\delta\left(T, \mathrm{H}_{\mathrm{b}}\right)$ between the transition metal and the hydrogen bridge is almost as large as $\delta(T, \mathrm{~B})$. This means that $T$ shares more pairs with the members of the $T$-H-B bridge than with the 210 (unbridged) boron of the direct contact. The interaction of the $T$ metal with the $\mathrm{Cp}$ ring is reflected by $\delta(T, \mathrm{C})$ between 0.3-0.4 giving a total DI of 1.5-2.0 for the electron sharing between $T$ and $C p$. For completeness it should be mentioned that the DIs $\delta(\mathrm{B}, \mathrm{B})$ and $\delta\left(\mathrm{B}, \mathrm{H}_{\mathrm{t}}\right)$ for the boron 215 atom with a neighboring boron and the terminal hydrogen, respectively, are around 0.6 .

\subsection{Covalent bond order}

The canonical orbitals from the DFT calculations can be transformed into so-called localized natural orbitals (LN@) from which a topological variant of covalent bond order can be computed.[27] The localization criterion for the LNO determination is to maximize the sum $L$ of squared orbital populations within all QTAIM basins:

$$
L=\sum_{m} \sum_{i} S_{m m}\left(A_{i}\right)^{2}
$$

The optimal orbitals (LNOs) yielding miximal $L$ are given by a unitary rotation (for single determinant, otherwise the natural occupations are involved and the rotation is no more unitary). The covalent bond order $\beta\left(A_{1}, A_{2}\right)$ between the QTAIM basins $A_{1}$ and $A_{2}$ :

$$
\beta\left(A_{i}, A_{j}\right)=2 \sum_{m} S_{m m}\left(A_{i}\right) S_{m m}\left(A_{j}\right)
$$

is given by the sum of products of the LNO populations $S_{m m}$ of the involved basins. This bond order variant is connected with the DIs, cf. Eq. 2, by omitting the nondiagonal parts included in the DI definition (in the LNO representation).[38] Thus, for LNOs strongly orthogonal within the atomic basins, the covalent bond order is very close to the corresponding DI.

Table 6: Covalent Bond Orders $\beta(T, A)$ Between the Transition 225 Metal $T$ and the Atomic Region $A$.

\begin{tabular}{cccccc}
\hline $\mathrm{cpd}$ & $\beta\left(T, T^{\prime}\right)$ & $\beta(T, \mathrm{~B})$ & $\beta\left(T, \mathrm{~B}_{\mathrm{b}}\right)$ & $\beta\left(T, \mathrm{H}_{\mathrm{b}}\right)$ & $\beta(T, \mathrm{C})$ \\
\hline $\mathbf{1}$ & 1.05 & 0.52 & 0.30 & 0.36 & 0.32 \\
$\mathbf{2}$ & 1.18 & 0.72 & 0.34 & 0.43 & 0.37 \\
$\mathbf{3}$ & 0.94 & 0.77 & 0.38 & 0.46 & 0.36 \\
$\mathbf{4}$ & 0.71 & 0.51 & 0.32 & 0.37 & 0.29 \\
$\mathbf{5}$ & 0.88 & 0.73 & 0.39 & 0.47 & 0.36 \\
$\mathbf{6}$ & 0.84 & 0.83 & 0.59 & 0.63 & 0.40 \\
\hline
\end{tabular}

The metal-metal covalent bond orders $\beta\left(T, T^{\prime}\right)$ from $_{235}$ 0.7 up to 1.2 , cf. the values compiled in Table 6 , highlight the importance of bonding interaction between the transition metals. The bond orders can be decomposed into orbital contributions. Interestingly, such a decomposition of the $\beta\left(T, T^{\prime}\right)$ shows that although the bond order is close $\mathrm{to}_{240}$ 1, between 2-4 LNOs are needed to recover the main part of the bond order. Of course, using all overlap integrals for the LNOs will recover the same DIs as the canonical orbitals. The much lower $\delta\left(T, T^{\prime}\right)$ values than the bond orders $\beta\left(T, T^{\prime}\right)$ show that the LNOs are not orthogonal to each other within the metal basins. This is a bonding situation different from the one for the bonds between $T$ and the other elements as well as B-B and B-H bonds, respectively. Except the values for the $T-T$ bond, the bond orders in Table 6 are very close to the corresponding DIs given in Table 5 .

\subsection{Fermi orbitals}

Further inside into the nature of the $T-T$ bond can be gained by the inspection of the Fermi orbitals (FO). [2426] The domain-averaged Fermi-hole (DAFH) analysis is based on the diagonalization of the hole-density $\rho_{h}^{A}\left(\vec{r}_{1}\right)$, which is recovered from the integral of the pair density over chosen reference domain $A$ (usually a QTAIM basin):

$$
\begin{aligned}
\rho_{h}^{A}\left(\vec{r}_{1}\right) & =\rho\left(\vec{r}_{1}\right) \int_{A} \rho\left(\vec{r}_{2}\right) d \vec{r}_{2} \\
& -\int_{A} \rho_{2}\left(\vec{r}_{1}, \vec{r}_{2}\right) d \vec{r}_{2}
\end{aligned}
$$

which for a single determinant can be written as (using the overlap integrals $S_{m n}(A)$ defined in previous sections):

$$
\rho_{h}^{A}(\vec{r})=\sum_{m n} S_{m n}(A) \phi_{m}(\vec{r}) \phi_{n}^{*}(\vec{r})
$$

The diagonalization of $\rho_{h}^{A}(\vec{r})$ yields the domain natural orbitals (DNO) and related occupation numbers. The DNOs are orthonormal orbitals that are orthogonal to each other also in the domain $A$. The DNOs are subjected to socalled (non-unitary) isopycnic transformation[40] yielding the Fermi orbitals $\varphi$ and the occupation numbers $n^{A}$ :

$$
\rho_{h}^{A}(\vec{r})=\sum_{m n} n_{k}^{A} \varphi_{k}(\vec{r}) \varphi_{k}^{*}(\vec{r})
$$

The Fermi orbitals (which are, in contrast to the DNOs, no more orthogonal to each other) are used to describe the interaction of electrons within the reference domain with the surrounding environment. Here the FOs are utilized for the decomposition of the $T-T$ delocalization index into orbital contributions. The idea behind the DI decomposition[26] is immediately visible when comparing Eqs. 2 and 6 with Eq. 7 after the integration over another domain.

As the reference basin for the determination of the Fermi orbitals the QTAIM basin of one of the transition metal was used (the same one as used for the evaluation of the effective charge in Table 4). Because the DI between the reference basin and a second basin is given by the integral of the corresponding Fermi density over the second basin, and at the same time the Fermi density is represented by squared Fermi orbitals (weighted by the occupations), the DIs can easily be decomposed into the 
Table 7: Fermi-Orbital Contributions to the Transition-Metal Delocalization Index $\delta\left(T, T^{\prime}\right)$.

\begin{tabular}{cccccccccccccccccccc}
\hline & & $\mathrm{V}$ & \multicolumn{4}{c}{$\mathrm{Cr}$} & \multicolumn{4}{c}{$\mathrm{Mo}$} & \multicolumn{4}{c}{$\mathrm{Ta}$} & \multicolumn{4}{c}{$\mathrm{Re}$} \\
$\mathrm{FO}$ & $\mathrm{n}$ & $\delta$ & $\%$ & $\mathrm{n}$ & $\delta$ & $\%$ & $\mathrm{n}$ & $\delta$ & $\%$ & $\mathrm{n}$ & $\delta$ & $\%$ & $\mathrm{n}$ & $\delta$ & $\%$ & $\mathrm{n}$ & $\delta$ & $\%$ \\
\hline$s$ & 2.0 & 0.00 & 0 & 2.0 & 0.00 & 0 & 2.0 & 0.00 & 0 & 2.0 & 0.00 & 0 & 2.0 & 0.00 & 0 & 2.0 & 0.00 & 0 \\
$p$ & 2.0 & 0.00 & 0 & 2.0 & 0.00 & 0 & 2.0 & 0.00 & 0 & 2.0 & 0.00 & 0 & 2.0 & 0.00 & 0 & 2.0 & 0.00 & 0 \\
$T-T$ & 0.9 & 0.40 & 67 & 1.0 & 0.27 & 36 & 1.0 & 0.24 & 37 & 0.7 & 0.29 & 70 & 1.0 & 0.23 & 38 & 1.1 & 0.20 & 30 \\
$T-B 3$ & 0.9 & 0.12 & 21 & 1.0 & 0.09 & 13 & 1.0 & 0.14 & 22 & 0.7 & 0.07 & 16 & 0.9 & 0.11 & 19 & 1.0 & 0.11 & 16 \\
$T$-B2 & 0.3 & 0.00 & 0 & 1.0 & 0.18 & 25 & 1.0 & 0.07 & 11 & 0.3 & 0.00 & 1 & 0.8 & 0.05 & 9 & 0.9 & 0.04 & 6 \\
$T-\mathrm{B}$ & 0.3 & 0.04 & 7 & 0.2 & 0.07 & 10 & 0.3 & 0.11 & 18 & 0.3 & 0.03 & 7 & 0.5 & 0.16 & 27 & 0.5 & 0.21 & 32 \\
\hline & & 0.56 & 95 & & 0.61 & 84 & & 0.56 & 88 & & 0.39 & 94 & & 0.56 & 93 & & 0.55 & 85 \\
\hline
\end{tabular}

For the Fermi orbital with occupation $n$ the percentage $\% \delta$ of the contribution to the metal-metal DI is given.

contributions of the Fermi orbitals. Actually, the Fermi orbitals yield the minimal spread of such contributions.[26]

For the metal basins 4 FOs with the occupation $n=2$ can be detected (the $s$ and $p$ orbitals, due to the core potentials used for the DFT calculations). Those FOs are fully inside the reference basin and thus cannot contribute to the DIs, cf. Table 7. For all model systems there is one FO that can be attributed to the bond between the metals, see Fig. 3. This FO yields $67 \%$ and $70 \%$ of the $\delta\left(T, T^{\prime}\right)$ for the $\mathrm{V}$ and Ta complex, respectively. Although the occupation of this FO type is close to 1 for the other metal complexes, the contributions to the corresponding DIs $\delta\left(T, T^{\prime}\right)$ is only between $30 \%-38 \%$. This is because the

255 FOs spread more in the boron basins than in the neighbor metal basin. This can be nicely seen especially for the Re complex, see diagram 6 in Fig. 3, where the Re basin is included. To recover more of the $\delta\left(T, T^{\prime}\right)$ value, additional FO contributions must be taken into account. is easy for the $\mathrm{V}$ and Ta complexes where a second $\mathrm{FO}$ (with the same occupation as the $T$ - $T^{\prime}$ FO), describing the $T$-B3 bond, yields the contribution of $21 \%$ and $16 \%$, respectively. This means that these two FOs deliver almost $90 \%$ of the metal-metal DI. This FO type has large $\mathrm{DI}^{285}$ ming up to $46 \%-59 \%$ of the DI only. In this complex two additional FOs must be considered, both involving $T$-B interactions. Only then the sum of the contributions give more than $80 \%$ of $\delta\left(T, T^{\prime}\right)$.

Along the period, going from the $\mathrm{V}$ to the $\mathrm{Cr}$ complexes, respectively from the Ta to the Re complexes, the $\delta\left(T, T^{\prime}\right)$ indices increase, cf. Table 5 . However, at the same time, the electron pair sharing as given by the contribution of the FO describing the $T$ - $T^{\prime}$ 'bond decreases (both absolute and in percent of the total DI) because the FO becomes more confined to the reference basin. The increase of the $\delta\left(T, T^{\prime}\right)$ index is due to an increasing number of $T$ B FOs (following the increase of the metal $d$-population) spreading out into the metal basins.

\subsection{Electron localizability indicator}

The analysis of the electron sharing can be extended to the analysis of (local) electron pairing as shown by the electron localizability indicator in the ELI-D representation. $[28$,
29] ELID is based on so-called $\omega$-restricted space partitioning ( $\omega$ RSP). [41] Following the $\omega$ RSP approach the whole space is partitioned into compact non-overlapping infinitesimally small regions $\mu$ each enclosing (in case of ELI-D) a fixed amount $\omega_{D}$ of same-spin pairs:

$$
\omega_{D}=\iint_{\mu} \rho_{2}^{\sigma \sigma}\left(\vec{r}_{1}, \vec{r}_{2}\right) d \vec{r}_{1} d \vec{r}_{2} \approx \frac{1}{12} g^{\sigma}(\vec{a}) V_{\mu}^{8 / 3}
$$

with the $\sigma$-spin Fermi-hole curvature $g^{\sigma}(\vec{a})$ at the position $\vec{a}$ within $\mu$ having the volume $V_{\mu}$. ELI-D is the rescaled distribution of charges in such regions $\mu$. The charge $q$ in $\mu$ can be approximated by $q=\rho^{\sigma} V_{\mu}$, which after replacing for the volume from Eq. 8 yields in the limit after rescaling with the factor $\omega_{D}^{3 / 8}$ the $\sigma$-spin ELI-D value $\Upsilon_{D}^{\sigma}(\vec{r})$ :

$$
\Upsilon_{D}^{\sigma}(\vec{r})=\rho^{\sigma}(\vec{r})\left[\frac{12}{g^{\sigma}(\vec{r})}\right]^{3 / 8} .
$$

In this representation the indicator $\Upsilon_{D}^{\sigma}$ is proportional to the charge needed to form a fixed (infinitesimally small) fraction of the $\sigma \sigma$-spin electron pair. For the model systems (all closed-shell) high ELI-D values describe regions where the motion of same-spin electrons is strongly correlated, i.e., regions where same-spin electrons avoid each other. Such a high avoidance is typical in regions that are usually assigned to bonds, lone-pairs or atomic (core) shells.

Table 8: Electron Populations in the ELI-D Basins.

\begin{tabular}{cccccccc}
\hline cpd & $T$ & $T-T^{\prime}$ & B1-B2 & B2-B3 & $\mathrm{H}_{\mathrm{t}}$ & $\mathrm{H}_{\mathrm{b}}$ & $\mathrm{Cp}$ \\
\hline $\mathbf{1}$ & 10.66 & 0.16 & 1.84 & 2.28 & 1.98 & 1.85 & 35.45 \\
$\mathbf{2}$ & 11.78 & 0.12 & 2.29 & 2.55 & 1.99 & 1.87 & 35.42 \\
$\mathbf{3}$ & 11.11 & 0.30 & 2.38 & 2.78 & 2.01 & 1.92 & 35.55 \\
$\mathbf{4}$ & 9.74 & 0.35 & 1.97 & 2.51 & 1.99 & 1.93 & 35.67 \\
$\mathbf{5}$ & 10.48 & 0.44 & 2.40 & 3.12 & 2.01 & 1.95 & 35.66 \\
$\mathbf{6}$ & 11.33 & 0.31 & 2.67 & 2.62 & 2.03 & 1.88 & 35.65 \\
\hline
\end{tabular}

See Fig. 2 for boron atom numbering.

Fig. 4 shows exemplary the ELI-D localization-domains, i.e., isosurfaces of chosen isovalue, for the $\mathrm{W}$ and Re complexes. The boron and carbon cores are represented by small spherical domains around the atomic positions. The corresponding ELI-D core basins enclose about 2.09 electrons. The B-B and C-C bonds are clearly visible as the 


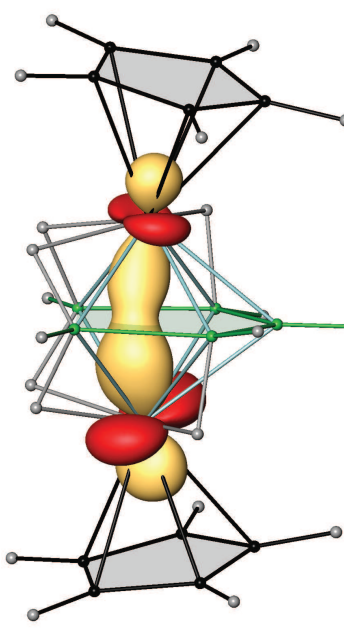

1

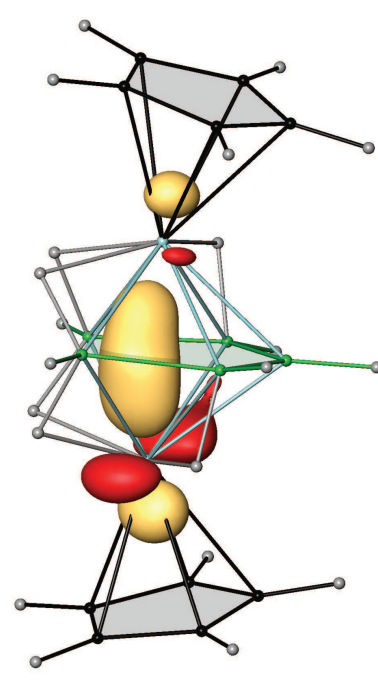

4

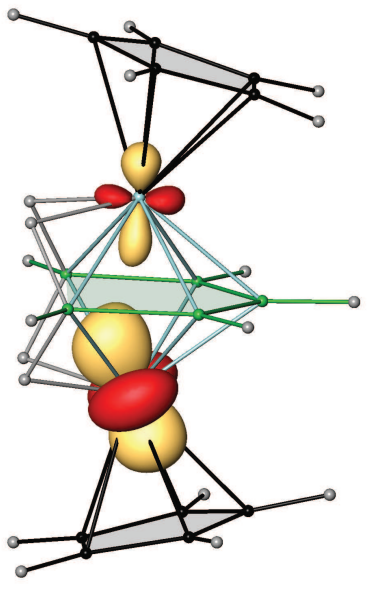

2

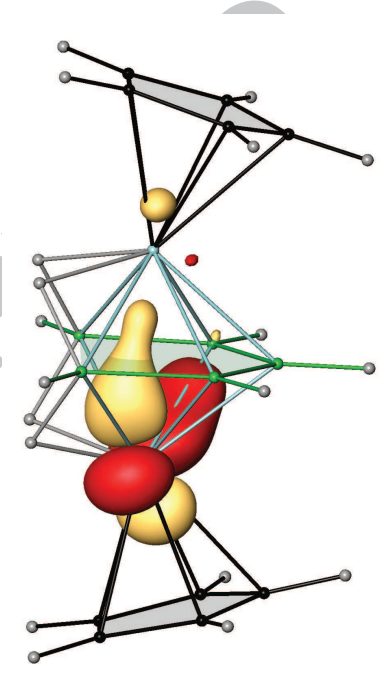

5

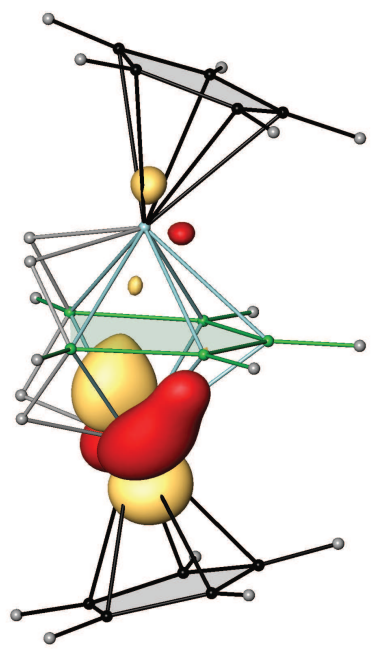

3

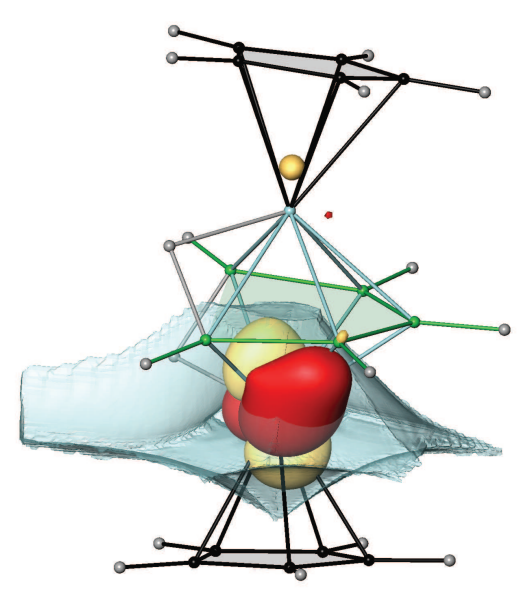

6

Figure 3: Fermi orbitals (isovalue \pm 0.1 ) describing the $T$ - $T$ ' bond for the model systems 1-6. The atoms are represented by spheres (transition metal: blue; carbon: black; boron: green; hydrogen: gray). For the compound $\mathbf{6}$ the Re basin is shown as a transparent object. 


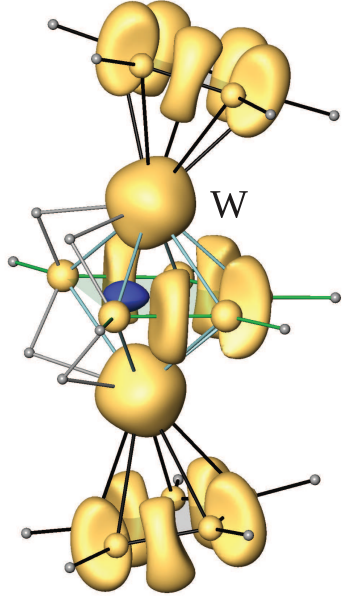

5

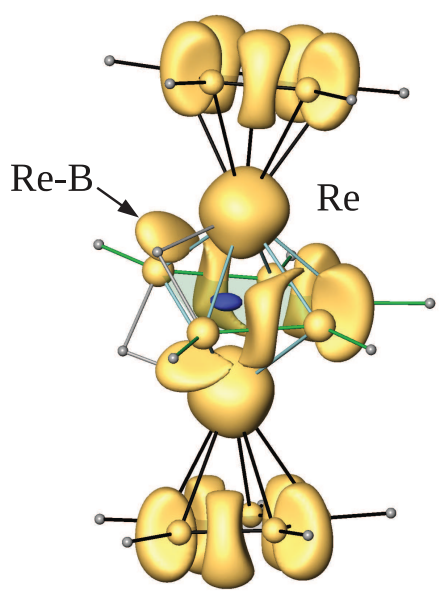

6
Figure 4: ELI-D localization domains for the model systems 5 and $\mathbf{6}$ (yellow: $\Upsilon_{D}^{\alpha}=1.36$; blue: $\Upsilon_{D}^{\alpha}=1.06$ ). The domain corresponding to the Re-B is marked by the arrow.

domains positioned between the atomic cores. The ELI- $\mathrm{D}_{350}$ basins for the carbon cores, together with the basins for the $\mathrm{C}-\mathrm{C}$ bonds $(2.82-2.87 \mathrm{e})$ and the hydrogens $(2.17 \mathrm{e})$ (the hydrogen domains were excluded in Fig. 4 for better visibility) constitute the Cp superbasin populated by roughly 35.5 electrons. This relates effectively a negative charge of -0.4 e to -0.7 e to the $\mathrm{Cp}$ group, cf. Table 8 . This is around twice the effective charge for the $\mathrm{Cp}$ group as given by the QTAIM partitioning, cf. Table 4.

The ELI-D basins for terminal hydrogens of the boron chains are populated almost exactly by two electrons, irrespective of the model system examined. Similarly, the basin populations for the hydrogens $\mathrm{H}_{\mathrm{b}}$ bridging the $T$-B contacts show relatively constant values close to 1.9 electrons. On the contrary, there are two distinct ELI-D basins for the B-B bonds. Except for the Re complex, the B1$\mathrm{B} 2$ bonding basin is populated by up to 0.7 electrons less (in the $\mathrm{W}$ complex) than the B2-B3 basin. In the Re $\mathrm{B}^{360}$ complex those two populations are almost identical. Howa new ELI-D bonding feature emerges. As marked in Fig. 4 two ELI-D maxima were found along the two unbridged Re-B contact to the terminal borons with a respective basin population of 1.44 electrons. This feature ${ }^{365}$ is not present for any other unbridged $T$-B contact of the examined series.

The existence of the $T-T^{\prime}$ bond is supported by the ELI-D maximum in the boron plane between the transi- ${ }^{370}$ tion metals, cf. the blue colored domain in Fig. 4. The corresponding $T$ - $T$ ' bonding basins are populated by $0.12-$ bonds. The T-T' populations are largest for the Group ${ }^{375}$ 6 metal complexes. Observe, that the population of the transition-metal core-basins, cf. Fig. Table 8 decreases along the group. For instance, for $\mathrm{Cr}$, Mo, and $\mathrm{W}$ it

330 amounts to $11.78 \mathrm{e}, 11.11 \mathrm{e}$, and $10.48 \mathrm{e}$, respectively, which can be compared to the 12 electrons expected from the position in the Periodic Table (core potentials were used).

\section{Conclusion}

The analysis of the $T-T$ bonding interactions in the $\mathrm{Cp}_{2} T_{2} \mathrm{~B}_{5} \mathrm{H}_{5+x}$ model series used to mimic the oblato-nido dimetallaboranes $\mathrm{Cp}_{2}^{*} T_{2} B_{5} \mathrm{H}_{5+x}(T=\mathrm{V}$, Ta, Cr, Mo, $\mathrm{W}, \mathrm{Re}$ ) was examined applying several bonding indicators. Both through-space and through-bond (via the boron atoms of the ring) interactions account for a substantial metal-metal bond. The direct $T$ - $T$ bonding was confirmed by the presence of a bond path and an ELI-D bonding basin, populated by up to 0.4 electrons, between the transition metals. The evaluation of the delocalization indices between the QTAIM metal-basins clearly show an extent of electron-pair sharing typical for a metal-metal bond. This was additionally supported by the metal-metal covalent bond order around 1, as proposed earlier.[7] That the $T$ - $T$ bonding situation does not correspond to a simple single bond was confirmed by the calculation of Fermi orbitals, indicating that roughly 2-3 Fermi orbitals needed to be considered when recovering the delocalization indices.

\section{Acknowledgment}

B.B. thanks the Région de Bretagne (Ulysse grant) for his visit to Dresden. Prof. S. Ghosh (IIT Madras) is thanked for helpful discussions.

\section{Appendix A. Supplementary material}

Supplementary data associated with this article can be found, in the online version, at $\{$ doi $\}$.

\section{References}

\section{References}

[1] T. P. Fehlner, Exploring the interactions of d-block elements with boron. a case for electronically unsaturated metallaborane clusters, J. Chem. Soc. Dalton Trans. (1998) 15251531doi: 10.1039/A800924D.

[2] T. P. Fehlner, Systematic metallaborane chemistry, Organometallics 19 (2000) 2643-2651. doi:10.1021/om000355r.

[3] A. S. Weller, M. Shang, T. P. Fehlner, Synthesis of mono- and ditungstaboranes from reaction of $\mathrm{Cp}^{*} \mathrm{WCl}_{4}$ and $\left[\mathrm{Cp}^{*} \mathrm{WCl}_{2}\right]_{2}$ with $\mathrm{BH}_{3} \cdot$ thf or $\mathrm{LiBH}_{4}\left(\mathrm{Cp}^{*}=\eta^{5}-\mathrm{C}_{5} \mathrm{Me}_{5}\right)$. control of reaction pathway by choice of monoboron reagent and oxidation state of metal center, Organometallics 18 (1999) 53-64. doi: $10.1021 /$ om $980743 \mathrm{~h}$

[4] D. K. Roy, S. K. Bose, K. Geetharani, K. K. V. Chakrahari, S. M. Mobin, S. Ghosh, Synthesis and structural characterization of new divanada- and diniobaboranes containing chalcogen atoms, Chem. Eur. J. 18 (2012) 9983-9991. doi : 10.1002/chem. 201200189. 
5] S. K. Bose, K. Geetharani, B. Varghese, S. M. Mobin, S. Ghosh, Metallaboranes of the early transi-450 tion metals: Direct synthesis and characterization of $\left[\left(\eta^{5}-\mathrm{C}_{5} \mathrm{Me}_{5}\right) \mathrm{Ta}_{2} \mathrm{~B}_{\mathrm{n}} \mathrm{H}_{\mathrm{m}}\right] \quad(\mathrm{n}=4, \mathrm{~m}=10 ; \mathrm{n}=5, \mathrm{~m}=11)$, $\left[\left(\eta^{5}-\mathrm{C}_{5} \mathrm{Me}_{5}\right) \mathrm{Ta}_{2} \mathrm{~B}_{5} \mathrm{H}_{10}\left(\mathrm{C}_{6} \mathrm{H}_{4} \mathrm{CH}_{3}\right)\right]$,

$\left[\left(\eta^{5}-\mathrm{C}_{5} \mathrm{Me}_{5}\right) \mathrm{TaCl}_{2} \mathrm{~B}_{5} \mathrm{H}_{11}\right]$, Chem. Eur. J. 14 (2008) 90589064. doi:10.1002/chem. 200800487.

[6] S. Aldridge, T. P. Fehlner, M. Shang, Directed synthesis of chromium and molybdenum metallaborane clusters. preparation and characterization of $\left(\mathrm{Cp}^{*} \mathrm{Cr}\right)_{2} \mathrm{~B}_{5} \mathrm{H}_{9},\left(\mathrm{Cp}^{*} \mathrm{Mo}\right)_{2} \mathrm{~B}_{5} \mathrm{H}_{9}$, and $\left(\mathrm{Cp}^{*} \mathrm{MoCl}\right)_{2} \mathrm{~B}_{4} \mathrm{H}_{10}$, J. Am. Chem. Soc. 119 (1997) 23392340. doi:10.1021/ja963864m.

B. Le Guennic, H. Jiao, S. Kahlal, J.-Y. Saillard, J.-F. Halet, S. Ghosh, M. Shang, A. M. Beatty, A. L. Rheingold, T. P. Fehlner, Synthesis and characterization of hypoelectronic rhenaboranes. analysis of the geometric and electronic structures of species following neither borane nor metal cluster electron-465 counting paradigms, J. Am. Chem. Soc. 126 (2004) 3203-3217. doi:10.1021/ja039770b.

[8] R. B. King, Oblate deltahedra in dimetallaboranes: Geometry and chemical bonding, Inorg. Chem. 45 (14) (2006) 8211-8216. doi:10.1021/ic060922o.

[9] K. Wade, The structural significance of the number of skeletal bonding electron-pairs in carboranes, the higher boranes and borane anions, and various transition-metal carbonyl cluster compounds, Chem. Commun. (1971) 792793doi: 10.1039/C29710000792.

$405[10]$ D. M. P. Mingos, A general theory for cluster and ring compounds of the main group and transition elements, Nature Phys. Sci. 236 (1972) 99-102. doi:10.1038/physci236099a0.

[11] D. M. P. Mingos, Polyhedral skeletal electron pair approach, Acc. Chem. Res. 17 (1984) 311-319. doi:10.1021/ar00105a003.4

12] A. Lupan, R. B. King, Hypoelectronic dirhenaboranes having eight to twelve vertices: Internal versus surface rhenium-rhenium bonding, Inorg. Chem. 51 (2012) 7609-7616. doi:10.1021/ic300458w.

[13] R. B. King, Some examples of unusual skeletal bonding topolo-485 gies in metallaboranes containing two or three early transition metal vertices, Inorg. Chem. 40 (12) (2001) 2699-2704. doi:10.1021/ic001320m

[14] T. P. Fehlner, J.-F. Halet, J.-Y. Saillard, Molecular Clusters: A Bridge to Solid State Chemistry, Cambridge University Press,490 Cambridge, UK, 2007.

15] R. B. King, Geometry and chemical bonding in polyhedral boranes, metallaboranes, and dimetallaboranes: From closo to isocloso to oblatocloso polyhedra, J, Organomet. Chem. 694 (2009) 1602-1606. doi:10.1016/j.jorganchem.2008.12.060.

16] R. B. King, S. Ghosh, Chemical bonding in oblatonido ditantalaboranes and related compounds, Theor. Chem. Acc. 131 (2) (2012) 1-8. doi:10.1007/s00214-012-1087-0.

[17] B. S. Krishnamoorthy, A. Thakur, K. K. V. Chakrahari, S. K. Bose, P. Hamon, T. Roisnel, S. Kahlal, S. Ghosh, J.-F. Halet,500 Theoretical and experimental investigations on hypoelectronic heterodimetallaboranes of group 6 transition metals, Inorg. Chem. 51 (2012) 10375-10383. doi:10.1021/ic301571e.

[18] K. Geetharani, B. S. Krishnamoorthy, S. Kahlal, S. M. Mobin, J.-F, Halet, S. Ghosh, Synthesis and characterization of hy-505 poelectronic tantalaboranes: Comparison of the geometric and electronic structures of $\left[\left(\mathrm{Cp}^{*} \mathrm{TaX}\right)_{2} \mathrm{~B}_{5} \mathrm{H}_{11}\right](\mathrm{X}=\mathrm{Cl}, \mathrm{Br}$, andI $)$, Inorg. Chem. 51 (2012) 10176-10184. doi:10.1021/ic300848f.

[19] J.-F. Halet, J.-Y. Saillard, 9.31 - theoretical treatment of ligated clusters containing transition metals, Reedijk, J.; Poeppelmeier.510 K. (Eds.), Comprehensive Inorganic Chemistry II: From Elements to Applications, Elsevier: Oxford, 20139 (2013) 869-885.

20] B. S. Krishnamoorthy, S. Kahlal, B. L. Guennic, J.-Y. Saillard, S. Ghosh, J.-F. Halet, Molecular transition-metal boron compounds. any interest?, Solid State Sci. 14 (2012) 1617-1623.515 doi: $10.1016 / \mathrm{j}$.solidstatesciences.2012.03.026.

[21] R. F. W. Bader, Atoms in Molecules - A Quantum Theory, Oxford University Press, Oxford, 1990

[22] R. F. W. Bader, M. E. Stephens, Spatial localization of the electronic pair and number distributions in molecules, J. Am. Chem. Soc. 97 (1975) 7391-7399. doi:10.1021/ja00859a001.

23] X. Fradera, M. A. Austen, R. F. W. Bader, The lewis model and beyond, J. Phys. Chem. A 103 (1999) 304-314. doi:10.1021/jp983362q

[24] R. Ponec, Electron pairing and chemical bonds. chemical structure, valences and structural similarities from the analysis of the fermi holes, J. Math. Chem. 21 (1997) 323-333. doi: 10.1023/A : 1019186806180 .

[25] R. Ponec, Electron pairing and chemical bonds. molecular structure from the analysis of pair densities and related quantities, J. Math. Chem. 23 (1998) 85-103. doi:10.1023/A:1019160922535.

[26] A. I. Baranov, R. Ponec, M. Kohout, Domain-averaged fermihole analysis for solids, J. Chem. Phys. 137 (21) (2012) 214109. doi: $10.1063 / 1.4768920$

[27] J. Cioslowsky, S. T. Mixon, Covalent bond orders in the topological theory of atoms in molecules, J. Am. Chem. Soc. 113 (1991) 4142-4145. doi:10.1021/ja00011a014.

[28] M. Kohout, A measure of electron localizability, Int. J. Quantum Chem. 97 (2004) 651-658. doi:10.1002/qua.10768.

[29] M. Kohout, Bonding indicators from electron pair density functionals, Faraday Discuss. 135 (2007) 43-54. doi: $10.1039 /$ b605951c.

[30] M. J. Frisch, G. W. Trucks, H. B. Schlegel, G. E. Scuseria, M. A. Robb, J. R. Cheeseman, G. Scalmani, V. Barone, B. Mennucci, G. A. Petersson, H. Nakatsuji, M. Caricato, X. Li, H. P. Hratchian, A. F. Izmaylov, J. Bloino, G. Zheng, J. L. Sonnenberg, M. Hada, M. Ehara, K. Toyota, R. Fukuda, J. Hasegawa, M. Ishida, T. Nakajima, Y. Honda, O. Kitao, H. Nakai, T. Vreven, J. A. M. Jr., J. E. Peralta, F. Ogliaro, M. Bearpark, J. J. Heyd, E. Brothers, K. N. Kudin, V. N. Staroverov, R. Kobayashi, J. Normand, K. Raghavachari, A. Rendell, J. C. Burant, S. S. Iyengar, J. Tomasi, M. Cossi, N. Rega, J. M. Millam, M. Klene, J. E. Knox, J. B. Cross, V. Bakken, C. Adamo, J. Jaramillo, R. Gomperts, R. E. Stratmann, O. Yazyev, A. J. Austin, R. Cammi, C. Pomelli, J. W. Ochterski, R. L. Martin, K. Morokuma, V. G. Zakrzewski, G. A. Voth, P. Salvador, J. J. Dannenberg, S. Dapprich, A. D. Daniels, Ö. Farkas, J. B. Foresman, J. V. Ortiz, J. Cioslowski, D. J. Fox, Gaussian 09 Revision A.1, gaussian Inc. Wallingford CT 2009.

[31] A. D. Becke, Density-functional exchange-energy approximation with correct asymptotic behavior, Phys. Rev. A 38 (1988) 30983100. doi:10.1103/PhysRevA.38.3098.

[32] S. H. Vosko, L. Wilk, M. Nusair, Accurate spin-dependent electron liquid correlation energies for local spin density calculations: a critical analysis, Can. J. Phys. 58 (8) (1980) 1200-1211. doi: $10.1139 / \mathrm{p} 80-159$.

[33] J. P. Perdew, Density-functional approximation for the correlation energy of the inhomogeneous electron gas, Phys. Rev. B 33 (1986) 8822-8824. doi:10.1103/PhysRevB.33.8822.

[34] M. Kohout, Dgrid version 4.6, Radebeul (2014).

[35] M. Kohout, A. Savin, H. Preuss, Contribution to the electron distribution analysis. i. shell structure of atoms, J. Chem. Phys. 95 (1991) 1928-1942. doi:10.1063/1.460989.

[36] P. Macchi, A. Sironi, Chemical bonding in transition metal carbonyl clusters: complementary analysis of theoretical and experimental electron densities., Coord. Chem. Rev. 238-239 (2003) 383-412. doi:10.1016/S0010-8545(02)00252-7.

[37] E. Espinosa, I. Alkorta, J. Elguero, E. Molins, From weak to strong interactions: A comprehensive analysis of the topological and energetic properties of the electron density distribution involving $\mathrm{X}-\mathrm{H} \cdots \mathrm{F}-\mathrm{Y}$ systems, J. Chem. Phys. 117 (2002) 5529-5542. doi:10.1063/1.1501133.

[38] J. G. Ángyán, M. Loos, I. Mayer, Covalent bond orders and atomic valence indices in the topological theory of atoms in molecules, J. Phys. Chem. 98 (1994) 5244-5248. doi:10.1021/j100071a013.

[39] R. Ponec, C. Gatti, Do the structural changes defined by the electron density topology necessarily affect the picture of the bonding? Inorg. Chem. 48 (2009) 11024-11031. doi:10.1021/ic901197b. 
520 [40] J. Cioslowsky, Isopycnic orbital transformations and localization of natural orbitals, Int. J. Quantum Chem. Symp. 24 (1990) 15-28.

[41] A. Martín Pendás, M. Kohout, M. A. Blanco, E. Francisco, in: C. Gatti, P. Macchi (Eds.), Modern charge-density analysis, Springer Dordrecht, Heidelberg, London, New York, 2012. 

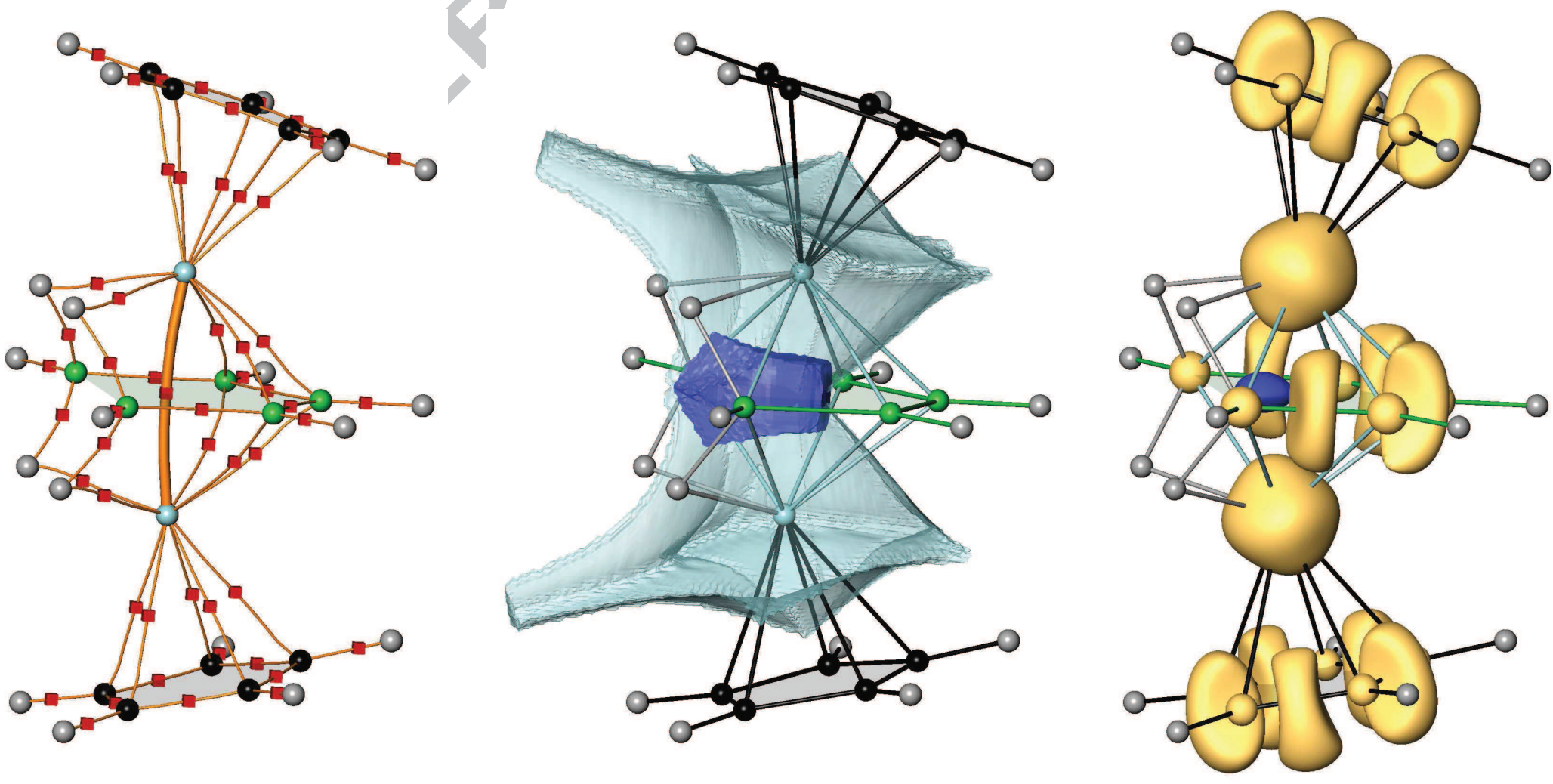
* Transition-metal bonding in oblato-nido metallaboranes was investigated.

* Confirmation of through-space as well as through-bond interactions.

* Description of direct metal-metal bonding through a boron ring.

* Application of real space topological methods. 